OPEN ACCESS

Edited by:

Scott C. Peck,

University of Missouri, USA

Reviewed by:

Giridara Kumar Surabhi,

Regional Plant Resource Centre, India

Alex Jones,

University of Warwick, UK

${ }^{*}$ Correspondence:

Renier A. L. van der Hoorn renier.vanderhoorn@plants.ox.ac.uk

Specialty section:

This article was submitted to

Plant Proteomics,

a section of the journal

Frontiers in Plant Science

Received: 09 July 2016 Accepted: 18 January 2017

Published: 03 February 2017

Citation:

Kovács J, Poór P, Kaschani F,

Chandrasekar B, Hong TN, Misas-Villamil JC, Xin BT, Kaiser M,

Overkleeft HS, Tari I and

van der Hoorn RAL (2017)

Proteasome Activity Profiling

Uncovers Alteration of Catalytic $\beta 2$

and $\beta 5$ Subunits of the

Stress-Induced Proteasome during

Salinity Stress in Tomato Roots.

Front. Plant Sci. 8:107.

doi: 10.3389/fpls.2017.00107

\section{Proteasome Activity Profiling} Uncovers Alteration of Catalytic $\beta 2$ and $\beta 5$ Subunits of the Stress-Induced Proteasome during Salinity Stress in Tomato Roots

\author{
Judit Kovács ${ }^{1}$, Péter Poór ${ }^{1}$, Farnusch Kaschani², Balakumaran Chandrasekar ${ }^{3,4}$, \\ Tram N. Hong ${ }^{3,4}$, Johana C. Misas-Villamil4,5, Bo T. Xin ${ }^{6}$, Markus Kaiser $^{2}$, \\ Herman S. Overkleeft ${ }^{6}$, Irma Tari' ${ }^{1}$ and Renier A. L. van der Hoorn ${ }^{3,4 *}$
}

${ }^{1}$ Department of Plant Biology, University of Szeged, Szeged, Hungary, ${ }^{2}$ Chemical Biology, Fakultät für Biologie, Zentrum für Medizinische Biotechnologie, Universität Duisburg-Essen, Essen, Germany, ${ }^{3}$ Plant Chemetics Laboratory, Department of Plant Sciences, University of Oxford, Oxford, UK, ${ }^{4}$ Plant Chemetics Laboratory, Max Planck Institute for Plant Breeding Research, Cologne, Germany, ${ }^{5}$ Botanical Institute and Cluster of Excellence on Plant Sciences, University of Cologne, Cologne, Germany, ${ }^{6}$ Leiden Institute of Chemistry, Leiden University, Leiden, Netherlands

The stress proteasome in the animal kingdom facilitates faster conversion of oxidized proteins during stress conditions by incorporating different catalytic $\beta$ subunits. Plants deal with similar kind of stresses and also carry multiple paralogous genes encoding for each of the three catalytic $\beta$ subunits. Here, we investigated the existence of stress proteasomes upon abiotic stress (salt stress) in tomato roots. In contrast to Arabidopsis thaliana, tomato has a simplified proteasome gene set with single genes encoding each $\beta$ subunit except for two genes encoding $\beta 2$. Using proteasome activity profiling on tomato roots during salt stress, we discovered a transient modification of the catalytic subunits of the proteasome coinciding with a loss of cell viability. This stress-induced active proteasome disappears at later time points and coincides with the need to degrade oxidized proteins during salt stress. Subunit-selective proteasome probes and MS analysis of fluorescent 2D gels demonstrated that the detected stress-induced proteasome is not caused by an altered composition of subunits in active proteasomes, but involves an increased molecular weight of both labeled $\beta 2$ and $\beta 5$ subunits, and an additional acidic pl shift for labeled $\beta 5$, whilst labeled $\beta 1$ remains mostly unchanged. Treatment with phosphatase or glycosidases did not affect the migration pattern. This stress-induced proteasome may play an important role in PCD during abiotic stress.

Keywords: 20S proteasome, immune proteasome, activity-based protein profiling, programmed cell death, salt stress, tomato root, catalytic subunit

\section{INTRODUCTION}

The proteasome plays a key role in protein degradation of cytonuclear proteins during biotic and biotic stress in plants. The $26 \mathrm{~S}$ proteasome is a highly conserved protein complex which has a crucial role in selective protein degradation during cell death and development. The $26 \mathrm{~S}$ proteasome consists of a catalytic 20S core protease and a 19S regulatory particle (Coux, 1996;

Abbreviations: ABPP, activity-based protein profiling; IEF, isoelectric focusing; PCD, programmed cell death; PLCP, papainlike Cys protease; PTM, post-translational modification; ROS, reactive oxygen species 
Kurepa and Smalle, 2008). The core protease is composed of four heptameric rings; two outer $\alpha$-rings and two inner $\beta$-rings, each of them composed of seven different $\alpha$ - and $\beta$ subunits (Löwe et al., 1995). These four heptameric rings are arranged as a cylinder with three large internal chambers. The active sites are in the central chamber, residing in three catalytic subunits: $\beta 1, \beta 2$, and $\beta 5$ which cleave after acidic, basic, and hydrophobic residues and representing caspase-like, trypsin-like, and chymotrypsinlike activities, respectively (Löwe et al., 1995; Kurepa and Smalle, 2008; Murata et al., 2009).

In addition to the standard $\beta 1, \beta 2$, and $\beta 5$ subunits, animals have additional "immuno"-subunits $(\beta 1 \mathrm{i}, \beta 2 \mathrm{i}$, and $\beta 5 \mathrm{i})$ and a thymus-specific subunit ( $\beta 5 \mathrm{t}$; Klare et al., 2007; Murata et al., 2007). Replacement of standard catalytic subunits by the catalytic "immuno"-subunits creates the immune proteasome (i-20S; Aki et al., 1994). These "immuno"-subunits can also co-exist with standard subunits within the same proteasome complex, creating an intermediate-type proteasome (Klare et al., 2007). Intermediate- and immune proteasomes play roles in the degradation of damaged and misfolded proteins during cell death and disease in animals (Zheng et al., 2012; Grigoreva et al., 2015).

Interestingly, there are indications of the existence of an alternative proteasome in plants. A defense-induced $\beta 1$ subunit $(\beta 1 \mathrm{din})$ in tobacco suggests the presence of a "defense proteasome" in plants (Suty et al., 2003). Transcripts of $\beta 1$ din accumulate during the elicitin-induced response in tobacco (Lequeu et al., 2005) whereas salicylic acid signaling activates the proteasome post-translationally (Gu et al., 2010). But little is known about modification and activation of specific proteasome subunits in plants. An optimal 26S proteasome is essential for maintaining plant drought stress tolerance (Cho et al., 2008; Yee and Goring, 2009). For instance, regulatory particle mutants have increased oxidative stress tolerance (Kurepa et al., 2008), and rpn1a mutants have increased salt hypersensitivity (Wang et al., 2009).

In this study, we investigated the proteasome during abiotic stress. We focused our studies on salt stress-induced PCD in tomato roots. The root is the primary organ recognizing salt stress and initiating signaling pathways. A moderate salt concentration stops root growth but higher salt concentrations can induce PCD, characterized by an oxidative burst, cytochrome c release, and DNA fragmentation (Giannattasio et al., 2008; Shabala, 2009; Andronis and Roubelakis-Angelakis, 2010), all triggered by sodium ions entering the cell (Shabala, 2000; Zhu, 2001). PCD in root tips upon salt stress is thought to be a defensive response during development to maintain the integrity of the root system (Hasegawa et al., 2000; Huh et al., 2002; Gémes et al., 2011). However, when lethal salt exposure is prolonged, it leads to death not only at the cellular level but also at tissue or organ level (Bagniewska-Zadworna and Arasimowicz-Jelonek, 2016).

Here, we tested the hypothesis that also plants have a stressinduced proteasome. We used ABPP (Cravatt et al., 2008) and proteomics on salt-stress in tomato roots to investigate the molecular composition of this stress-induced proteasome. ABPP involves biotinylated or fluorescent chemical probes that react with the active site of enzymes in an activity-dependent manner, creating an irreversible covalent bond that facilitates detection and identification (Morimoto and Van der Hoorn, 2016). ABPP displays changes in the activity level of the enzymes upon different treatments, for instance in the activity of PLCPs and serine hydrolases upon biotic stress, or vacuolar processing enzymes and proteasome during PCD (Shabab et al., 2008; Kaschani et al., 2009; Gu et al., 2012; van der Linde et al., 2012; Misas-Villamil et al., 2013a,b; Sueldo et al., 2014). Our ABPP studies reveal previously unknown stress-associated modifications of the proteasome in tomato roots upon salt stress.

\section{MATERIALS AND METHODS}

\section{Bioinformatics}

Genes encoding the $\beta$ subunits of tomato were identified by BLASTp searches of the predicted proteome (ITAG release 2.40) for homologs of the seven Arabidopsis $\beta$ subunits at the SolGenomics website ${ }^{1}$. The $\beta 2$ a protein sequence was modeled onto polypeptide $\mathrm{H}$ of the structure of the yeast proteasome (2zcy, Groll et al., 2008) using Swiss Model $^{2}$ (Biasini et al., 2014). This $\beta 2$ a model was used in PyMol to replace the $\beta 2$ in the structure of the yeast proteasome. Only the surface of one ring of $\beta$ subunits was visualized and the various parts and residues were colored using PyMol. Further annotations were added using CorelDRAW. Transcript levels were extracted from published RNA sequencing experiments on different organs (The Tomato Genome Consortium, 2012).

\section{Plant Materials and Growth Conditions}

Tomato (Solanum lycopersicum L. cv "Rio Fuego") plants were germinated at $26^{\circ} \mathrm{C}$ for 3 days in the dark, and the seedlings were subsequently transferred to perlite for 2 weeks. Plants were grown hydroponically in a controlled environment in a greenhouse $\left(300 \mu \mathrm{mol} \mathrm{m} \mathrm{m}^{-2} \mathrm{~s}^{-1}\right.$ photon flux density with $12 / 12$ light/dark photoperiod, $25^{\circ} \mathrm{C}$, and $55-60 \%$ relative humidity) for 3 weeks (Poór et al., 2011). Tomato plants were treated with 0 -, 100-, and $250 \mathrm{mM} \mathrm{NaCl}$ in the nutrient solution $[2 \mathrm{mM}$ $\mathrm{Ca}\left(\mathrm{NO}_{3}\right)_{2}, 1 \mathrm{mM} \mathrm{MgSO}, 0.5 \mathrm{mM} \mathrm{KCl}, 0.5 \mathrm{mM}, \mathrm{KH}_{2} \mathrm{PO}_{4}$, $0.5 \mathrm{mM} \mathrm{Na}_{2} \mathrm{HPO}_{4}, 0.001 \mathrm{mM} \mathrm{MnSO}$, $0.005 \mathrm{mM} \mathrm{ZnSO}_{4}$, $0.0001 \mathrm{mM}\left(\mathrm{NH}_{4}\right)_{6} \mathrm{Mo}_{7} \mathrm{O}_{24}, 0.01 \mathrm{mM} \mathrm{H}_{3} \mathrm{BO}_{4}, 0.02 \mathrm{mM}$ Fe(III)EDTA]. Samples were made in at 9 a.m. and samples were taken in triplicate at 1,6 , and $24 \mathrm{~h}$ after salt exposure.

\section{FDA Staining}

Fluorescein diacetate (FDA; Sigma-Aldrich, St. Louis, MO, USA) was used to determine cell viability according to Gémes et al. (2011). Root tip segments were stained for $10 \mathrm{~min}$ at room temperature in the dark with $10 \mathrm{mM}$ FDA dissolved in $3 \mathrm{ml}$ $10 \mathrm{mM}$ 2-(N-morpholino)ethanesulfonic acid (MES) potassium chloride (KCl) buffer ( $\mathrm{pH}$ 6.15). After staining, the samples were washed two times in $10 \mathrm{~min}$ with $\mathrm{MES} / \mathrm{KCl}$ buffer ( $\mathrm{pH} 6.15)$. Fluorescence intensity was detected with Zeiss Axiovert $200 \mathrm{M}$ type fluorescent microscope (Carl Zeiss Inc., Jena, Germany)

\footnotetext{
${ }^{1}$ www.solgenomics.net

${ }^{2}$ swissmodel.expasy.org
} 
equipped with an $5 \mathrm{X}$ objective. Digital photographs were taken from the samples with a high-resolution digital camera (Axiocam HR, HQ CCD camera; Carl Zeiss Inc., Jena, Germany) using a filter set 10 (excitation 450-495 nm, emission 515-565 nm) or filter set 20HE (excitation: 535-585 nm, emission: 600-655 nm). The fluorescence emission (pixel intensity) was measured on digital images with AXIOVISION REL. 4.8 software (Carl Zeiss Inc., Munich, Germany).

\section{Small-Scale Labeling Reaction Sample Preparation}

Root tissue was homogenized in $50 \mathrm{mM}$ Tris buffer at $\mathrm{pH} 7.5$ containing $5 \mathrm{mM}$ DTT for labeling of the proteasome. The extract was mixed and centrifuged at $10000 \mathrm{~g}$ for $10 \mathrm{~min}$ at $4^{\circ} \mathrm{C}$ to remove cell debris and the supernatant was collected and used for labeling.

\section{Labeling of Proteasome Subunits}

Hundred microgram/milliliterprotein extract was labeled with $2 \mu \mathrm{M}$ MV151 for $3 \mathrm{~h}$ or $0.2 \mu \mathrm{M}$ MVB072 or co-labeled with $0.8 \mu \mathrm{M}$ LW124/MVB127 for $2 \mathrm{~h}$ at room temperature in the dark in $60 \mu \mathrm{l}$ total volume. Equal volumes of DMSO were added for the no-probe-control. For inhibition assays, extracts were preincubated with 50 or $100 \mu \mathrm{M}$ epoxomicin or $50 \mu \mathrm{M} \mathrm{N} 3 \beta 1$ or $\mathrm{N} 3 \beta 5$ or DMSO and these extracts were labeled with the suitable probe. The labeling reactions were stopped by adding gel loading buffer containing $\beta$-mercaptoethanol at $4 \mathrm{X}$ final concentration and heating at $95^{\circ} \mathrm{C}$ for $10 \mathrm{~min}$. The reaction mixture was separated on $15 \%$ SDS gel at $200 \mathrm{~V}$ for $75 \mathrm{~min}$. Labeled proteins were visualized by in-gel fluorescence scanning using a Typhoon 9400 Imager (GE Healthcare) ${ }^{3}$ using excitation and emission wavelengths of 532/580 nm for MV151, MVB072, and MVB127 and of 470/530 nm for LW124. 532/580 nm and 470/530 were overlaid and signals were quantified using Image $1.48 \mathrm{~V}$.

\section{IEF 2D SDS PAGE}

Labeled and precipitated proteins were resuspended in UTC buffer (8 M urea, $2 \mathrm{M}$ thiourea, 4\% (w/v) CHAPS, $1 \mathrm{~g}$ AG 501-X8 Resin) containing $1 \%(\mathrm{v} / \mathrm{v})$ ampholyte and $65 \mathrm{mM}$ DTT. Samples were isoelectrically focused on $7 \mathrm{~cm}$ immobilized $\mathrm{pH}$ gradient (IPG) 3-10 pH strips (BioRad-ReadyStrip ${ }^{\text {TM }}$ IPG Strips) using BioRad PROTEAN i12 IEF system with the following focusing conditions: $12 \mathrm{~h}$ passive rehydration; $250 \mathrm{~V}, 15 \mathrm{~min}$, rapid ramp; 4000 V, 1 h, slow ramp; 4000 V, 30000 Vhr, rapid ramp; $500 \mathrm{~V}$ hold. After focusing, IPG strips were equilibrated in IEF Equilibration buffer [6 M urea, 5\% SDS (w/v), 30\% glycerol (v/v)] containing $1 \%(\mathrm{w} / \mathrm{v})$ DTT, then in IEF Equilibration buffer containing $2.5 \%$ iodoacetamide $(\mathrm{w} / \mathrm{v})$. The second dimension electrophoresis was run on a $15 \%$ SDS gel. Gels were imaged using a Typhoon 9400 Imager (GE Healthcare) using excitation and emission wavelengths of 532/580 $\mathrm{nm}$. Images were quantified using Image $1.48 \mathrm{~V}$ by multiplication of the fluorescence intensity and the area of each of the spots $(n=3)$.

${ }^{3}$ http://www.gelifesciences.com

\section{In-Gel Digestion and MS}

Bands were excised by hand and treated with trypsin as described elsewhere (Shevchenko et al., 2006). Tryptic digests were desalted on home-made C18 StageTips as described (Rappsilber et al., 2007). After elution from the StageTips samples were dried using a vacuum concentrator (Eppendorf) and the peptides taken up in $10 \mu \mathrm{L} 0.1 \%$ formic acid solution. LC-MS/MS experiments were performed on an Orbitrap Elite instrument (Thermo, Michalski et al., 2012) that was coupled to an EASYnLC 1000 liquid chromatography (LC) system (Thermo). The LC was operated in the two-column mode. The home-made fused silica column equipped with a glass fiber frit (Maiolica et al., 2005) was packed with Reprosil-Pur 120 C18-AQ $3 \mu \mathrm{m}$ resin (Dr. Maisch) and connected to the analytical column via an UHPLC union (Upchurch; UH-432). The analytical column was a fused silica capillary $(75 \mu \mathrm{m} \times 25 \mathrm{~cm})$ with integrated PicoFrit emitter (New Objective) packed in-house with ReprosilPur 120 C18-AQ $3 \mu \mathrm{m}$ resin (Dr. Maisch). The analytical column was attached to a nanospray flex ion source (Thermo). The LC was equipped with two mobile phases: solvent A $(0.1 \%$ formic acid, FA, in UPLC grade water) and solvent B $(0.1 \% \mathrm{FA}$ in acetonitrile, ACN). Peptides were delivered to the pre-column via the integrated autosampler at a flow rate of $2-3 \mu \mathrm{l} / \mathrm{min}$ in $100 \%$ solvent A. Peptides were subsequently separated on the analytical column by running a 70 min gradient of solvents $\mathrm{A}$ and $\mathrm{B}$ (start with $7 \% \mathrm{~B}$; gradient $7-35 \% \mathrm{~B}$ for $60 \mathrm{~min}$; gradient $35-100 \%$ B for $5 \mathrm{~min}$ and $100 \%$ B for $5 \mathrm{~min}$ ) at a flow rate of $300 \mathrm{nl} / \mathrm{min}$. The mass spectrometer was operated using Xcalibur software (version $2.2 \mathrm{SP} 1.48$ ) and was set in the positive ion mode. Precursor ion scanning was performed in the Orbitrap analyzer (FTMS) in the scan range of $\mathrm{m} / \mathrm{z} 300-1,500$ and at a resolution of 120,000 with the internal lock mass option turned on (lock mass was $445.120025 \mathrm{~m} / \mathrm{z}$, polysiloxane; Olsen et al., 2005). Product ion spectra were recorded in a data dependent fashion in the ion trap (ITMS) in a variable scan range and at a rapid scan rate. The ionization potential (spray voltage) was set to $1.6-2.0 \mathrm{kV}$. Peptides were analyzed using a repeating cycle consisting of a full precursor ion scan $\left(1.0 \times 10^{6}\right.$ ions $)$ followed by 15 product ion scans $\left(1.0 \times 10^{4}\right.$ ions $)$ where peptides are isolated based on their intensity in the full survey scan (threshold of 500 counts) for tandem mass spectrum (MS2) generation that permits peptide sequencing and identification. CID collision energy was set to $35 \%$ for the generation of MS2 spectra. During MS2 data acquisition dynamic ion exclusion was set to $120 \mathrm{~s}$ with a maximum list of excluded ions consisting of 500 members and a repeat count of one. Ion injection time prediction, preview mode for the FTMS, monoisotopic precursor selection and charge state screening were enabled. Only charge states bigger than 1 were considered for fragmentation.

\section{Peptide and Protein Identification}

The recorded RAW files were processed in ProteomeDiscoverer 1.4 (PD14, Thermo). MS2 spectra were extracted using the Spectrum Selector node. Precursor selection was set to "use MS1 precursor." The mass range was set between 350 and 5,000 Da with a minimum peak count of 1 . Mass analyzer was set to "any" 
and MS order to "MS2." Activation type was set to "is CID" and Scan type was defined as "full" with ionization source set to "is nanospray." Selected spectra were submitted to the in house MASCOT server [version 2.4.1 (Perkins et al., 1999)] using the PD14 MASCOT node.

Tandem mass spectrum spectra data were searched against the tomato_ITAG.fasta database ${ }^{4}$ (version 2.3; 34725 entries). All searches included a contaminants database (as implemented in MASCOT and MaxQuant, 263 sequences). The contaminants database contains known MS contaminants and was included to estimate the level of contamination. Mascot and Andromeda searches allowed for oxidation of methionine residues (16 Da) and a static modification on cysteine (57 Da, alkylation with iodoacetamide). Enzyme specificity was set to Trypsin/P. The instrument type in MASCOT searches was set to ESI-TRAP and the mass tolerance was set to $\pm 10 \mathrm{ppm}$ for precursor mass and $\pm 0.35 \mathrm{Da}$ for product ion masses. MS2 spectra matches were then evaluated using the peptide validation node of PD14 with the standard settings [search against decoy database, target false discovery rate (FDR, strict): 0.01 and target FDR (released): 0.05]. The reported results were further filtered. On peptide level only peptides with a minimum confidence 'medium' were reported and on protein level only proteins with a minimum of at least two peptide hits were reported.

\section{Protein Phosphatase Treatment}

Sixty microliter of MVB072-labeled sample containing $1 \mathrm{M} \mathrm{NaCl}$, $25 \mathrm{mM} \mathrm{MgCl}_{2} 10 \mathrm{mM}$ DTT, and 12.5X protease inhibitor cocktail (Sigma) were treated with 1 or $5 \mu \mathrm{l}$ of alkaline phosphatase (Sigma P0114) and incubated at $37^{\circ} \mathrm{C}$ for $1 \mathrm{~h}$. Samples were analyzed on $16 \%$ SDS-PAGE, whereas the remainder of the sample were separated on $10 \%$ SDS-PAGE and transferred to polyvinylidene difluoride (PVDF) membrane for detection of phosphorylated MAPK using primary antibody, Phospho-p44/42 MAPK (Erk1/2) (Thr202/Tyr204) antibody (CST, \#9101) and secondary Goat anti-Rabbit IgG (Thermo, \#31466) and visualized using chemiluminescent substrates (SuperSignal West/Pico Chemiluminescent substrates, Thermo scientific).

\section{PNGaseF Treatment of Labeled Proteins}

Nine microliter of MVB072-labelled tomato root extract and Bovine Fetuin (Promega) were treated with $1 \mu \mathrm{l}$ of $10 \mathrm{X}$ glycoprotein denaturing buffer (New England BioLabs) and heated at $95^{\circ} \mathrm{C}$ for $5 \mathrm{~min}$. The denatured proteins were chilled on ice. Two microliter 10X GlycoBuffer (New England BioLabs), $2 \mu 1$ $10 \% \mathrm{NP} 40$ (Promega), and $6 \mu \mathrm{l} \mathrm{H}_{2} \mathrm{O}$ was added to the reaction. The mixture was treated with $1 \mu$ l PNGase F (New England BioLabs) or with $1 \mu \mathrm{l} \mathrm{H}_{2} \mathrm{O}$ and incubated at $37^{\circ} \mathrm{C}$ for $1 \mathrm{~h}$. Samples were analyzed on $16 \%$ SDS-PAGE.

\section{Protein Deglycosylation of Labeled Proteins}

Eighteen microliter of MVB072-labelled sample and Bovine Fetuin (Promega) were treated with $2 \mu \mathrm{l}$ of $10 \mathrm{X}$ denaturing

\footnotetext{
${ }^{4}$ solgenomics.net
}

solution (Promega) and heated at $95^{\circ} \mathrm{C}$ for $10 \mathrm{~min}$. The denatured proteins were chilled on ice for $5 \mathrm{~min}$. To the denatured samples $5 \mu \mathrm{l}$ of 10X Deglycosylation Reaction Buffer (Promega), $5 \mu \mathrm{l}$ of $10 \%$ NP40 (Promega), and $15 \mu l$ of water were added. Samples were treated with $5 \mu$ l of Protein Deglycosylation Mix (Promega PNGase F, O-Glycosidase, Neuraminidase, $\beta 1-4$ Galactosidase, $\beta$-N-Acetylglucosaminidase) and incubated at $37^{\circ} \mathrm{C}$ for $8 \mathrm{~h}$. Samples were analyzed on $16 \%$ SDS-PAGE.

\section{RESULTS}

\section{Tomato Has Eight Genes Encoding the Seven $\beta$ Subunits}

To investigate the tomato proteasome, we performed BLAST searches with the Arabidopsis $\beta$ subunits on the predicted tomato proteome ${ }^{5}$ and identified eight tomato genes encoding $\beta$ subunits. Phylogenetic analysis of the tomato and Arabidopsis $\beta$ subunits revealed that tomato genome has one gene for each of the $\operatorname{six} \beta$ subunits $(\beta 1, \beta 3, \beta 4, \beta 5, \beta 6$, and $\beta 7)$, and two genes encoding $\beta 2$ (Figure 1A). The two $\beta 2$ proteins in tomato ( $\beta 2 \mathrm{a}$ and $\beta 2 \mathrm{~b}$ ) are more closely related to each other when compared to the two $\beta 2$ proteins of Arabidopsis (PBB1 and $\mathrm{PBB} 2$ ), consistent with the fact that genome duplication occurred in each lineage, after divergence (The Tomato Genome Consortium, 2012). Tomato, however, must have lost the paralogous copies of each except one proteasome $\beta$ subunit. Sequence alignment with the Arabidopsis orthologs indicates that each of the eight tomato genes encodes a putative functional subunit, including an $\mathrm{N}$-terminal pro-domain for all subunits and catalytic Thr for the $\beta 1, \beta 2$, and $\beta 5$ subunits (Supplementary Figure S1).

The branch lengths indicate that the two $\beta 2$ subunits are substantially different (Figure 1A). Indeed, we counted 18 amino acid residues that differ between the mature $\beta 2 \mathrm{a}$ and $\beta 2 \mathrm{~b}$ subunits (Figure 1B). Most of these amino acid substitutions are biochemically dissimilar. To estimate if these variant residues can affect the proteolytic chamber, we generated a structural model of the tomato $\beta 2$ protein using the yeast proteasome ( $2 \mathrm{zcy}$, Groll et al., 2008) as a template. Mapping the residues that vary between $\beta 2 \mathrm{a}$ and $\beta 2 \mathrm{~b}$ onto the structural model revealed that none of the variant residues are exposed to the proteolytic chamber (Figure 1C). Interestingly, nearly all the variant residues reside on the outer surface and are likely solvent-exposed (Figure 1C).

To determine which of the $\beta$ subunit-encoding genes are expressed in different tissues, we mined RNAseq datasets for the transcript levels of each of these genes from RNAseq data (The Tomato Genome Consortium, 2012). As expected for subunits that assemble in stoichiometric complexes, transcript levels of each of the $\beta$ subunit genes are very similar, with the exception of $\beta 2 a$ transcripts, which accumulate 5 - to 10 -fold lower when compared to $\beta 2 b$ and the other $\beta$ subunit-encoding transcripts (Figure 1D). Nevertheless, detection of $\beta 2 a$ transcripts suggests that $\beta 2 a$ is not a pseudogene, but the transcript levels are low under normal conditions. The ratio between $\beta 2 a$ and $\beta 2 b$ transcript levels does not significantly change in different tissues

${ }^{5}$ www.solgenomics.org 


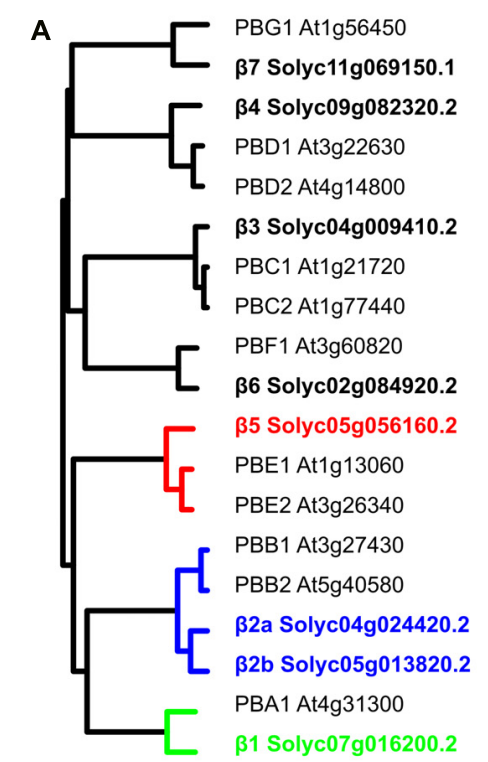

D

\begin{tabular}{|l|r|r|r|r|r|r|r|r|}
\hline & $\boldsymbol{\beta} 1$ & $\boldsymbol{\beta 2 a}$ & $\boldsymbol{\beta 2 b}$ & $\boldsymbol{\beta 3}$ & $\boldsymbol{\beta 4}$ & $\boldsymbol{\beta} 5$ & $\boldsymbol{\beta} 6$ & $\boldsymbol{\beta} 7$ \\
\hline Roots & 191 & 17 & 126 & 112 & 93 & 156 & 207 & 141 \\
\hline Leaves & 114 & 7 & 73 & 77 & 48 & 100 & 134 & 59 \\
\hline Flowers & 127 & 11 & 92 & 67 & 55 & 104 & 171 & 71 \\
\hline Green fruit & 89 & 17 & 80 & 87 & 48 & 100 & 134 & 102 \\
\hline Red fruit & 98 & 22 & 142 & 72 & 82 & 117 & 216 & 141 \\
\hline
\end{tabular}

B

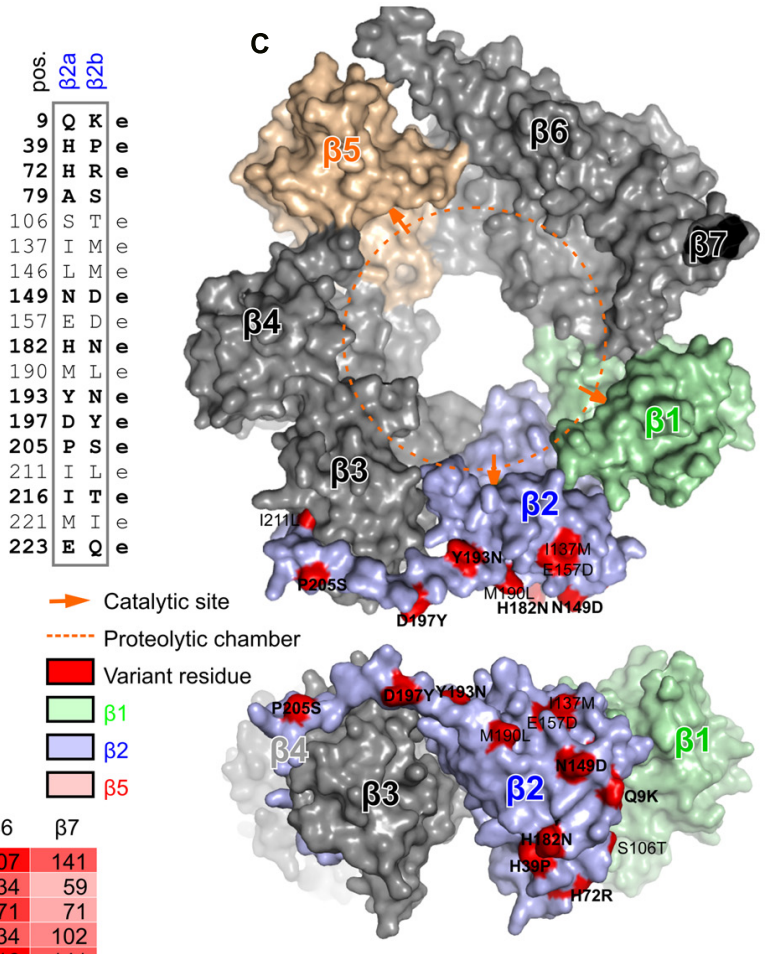

FIGURE 1 | Phylogeny and variation of beta proteasome subunits of tomato. (A) Phylogenetic tree of beta subunit genes of tomato and Arabidopsis. Neighbor-joining tree of protein sequences was build using ClustalW2. (B) Summary of the variant amino acid residues that differ between $\beta 2 \mathrm{a}$ and $\beta 2 \mathrm{~b}$. e, putative solvent-exposed. Significant variation is printed in bold. (C) Location of variant residues in $\beta 2$, modeled on the yeast proteasome. The tomato $\beta 2 a$ protein was modeled using the $\beta 2$ of yeast (2zcy) as a template. Residues that differ between $\beta 2 a$ and $\beta 2 \mathrm{~b}$ are highlighted in red in the topview (top) and sideview (bottom) of the $\beta$-ring of the proteasome and summarized in the table. The proteolytic chamber is highlighted with a dashed orange line and catalytic sites are indicated with orange arrows. (D) Transcript levels of $\beta$ subunit-encoding genes in various tomato organs. These data were extracted from The Tomato Genome Consortium (2012). Reads per kilobase of transcripts per million mapped reads (RPKM) values were extracted from the database for each gene.

(Figure 1D), suggesting that proteasome assembly might be similar for $\beta 2 \mathrm{a}$ and $\beta 2 \mathrm{~b}$ subunits in different tissues.

\section{Salt Treatment Induces Loss of Viability in Tomato Roots}

Salt stress is common in plants and is associated with the release of ROS. Higher salt concentration also triggers PCD (Hasegawa et al., 2000; Poór et al., 2014). To investigate salt stress in tomato roots, plants were treated with sublethal- $(100 \mathrm{mM})$ and lethal $(250 \mathrm{mM})$ concentrations of $\mathrm{NaCl}$ (Figure 2A). We studied the early stages of abiotic stress by collecting samples at 1,6 , and $24 \mathrm{~h}$ after salt exposure. Root tips were stained with FDA to detect and quantify viable cells. Low FDA staining after $6 \mathrm{~h}$ upon treatment with $250 \mathrm{mM} \mathrm{NaCl}$ indicates a massive and quick PCD that completes within $24 \mathrm{~h}$ (Figure 2B). By contrast, treatment with $100 \mathrm{mM} \mathrm{NaCl}$ caused a slower loss of viability, where decreased viability was detected only at $24 \mathrm{~h}$.

\section{MV151 Labeling Uncovers Differential Proteasome Activity}

Papain-like cysteine Proteases and the proteasome have been implicated in stress and PCD. To examine the activity of both PLCPs and the proteasome, we first tested MV151, which labels both the proteasome and a subset of the PLCPs (Gu et al., 2010). MV151 labeling causes weak signals at $30-40 \mathrm{kDa}$ which represent PLCPs and three stronger signals at $26 \mathrm{kDa}$ that may represent the active proteasome subunits or PLCPs (Figure 3A). Interestingly, we detected a strongly activated band at $\sim 26 \mathrm{kDa}$ with threefold higher intensity upon $250 \mathrm{mM}$ salt treatment at $6 \mathrm{~h}$ (Figure 3A). This extra signal was robustly detected in all biological replicates (Supplementary Figure S2), and statistically significant upon quantification of fluorescence intensities from the three biological replicates (Figure 3B). To determine if this signal is caused by the proteasome or PLCPs, a competition assay was performed using proteasome inhibitor epoxomicin and PLCP inhibitor E-64. Pre-incubation with E-64 suppresses labeling at $30-40 \mathrm{kDa}$ (Figure 3C), confirming that these signals are caused by PLCPs. The $26 \mathrm{kDa}$ signals are not suppressed by E-64 (Figure 3C), indicating that these signals might be from the proteasome. Indeed, pre-incubation with the selective proteasome inhibitor epoxomicin suppresses labeling of all $26 \mathrm{kDa}$ signals (Figure 3C), indicating that the significantly activated band is caused by the proteasome. Thus, although these MV151 labeling experiments did not display differential activities of PLCPs, it did uncover differential proteasome activity profiles. 

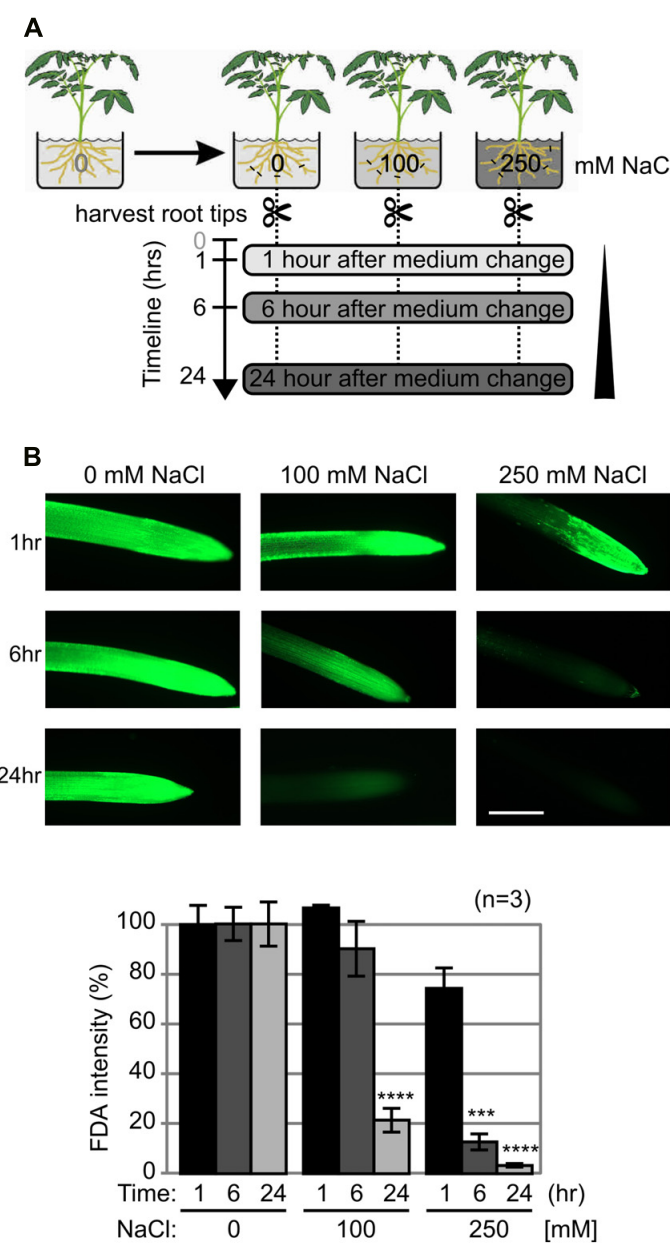

FIGURE 2 | Salt treatment induces loss of viability in tomato roots. (A) Experimental assay. Tomato (Solanum lycopersicum) plants were grown in a hydroponic system and 5-weeks old plants were treated with 0-, 100- and $250 \mathrm{mM} \mathrm{NaCl}$ in the nutrient solution. Root tips were collected at 1, 6, and $24 \mathrm{~h}$. (B) Loss of viability upon salt stress. Root tips were stained with fluorescein diacetate (FDA) to detect the viable cells. Top: representative images are shown. Scale bar, $0.5 \mathrm{~mm}$. Bottom: fluorescent intensities of FDA fluorescence levels, when compared to the control. Error bars represent SEM of $n=3$ biological replicates.

\section{Salt Stress Alters the Activity Profile of Proteasome Catalytic Subunits}

To confirm differential proteasome activity, we used a newly re-synthesized epoxomicin-based MVB072, which carries both a bodipy tag for fluorescent detection and a biotin tag for affinity purification (Kolodziejek et al., 2011). When compared to MV151, MVB072 is a much more selective proteasome probe without any known off targets, ideal to confirm differential proteasome activity in our samples (Kolodziejek et al., 2011). Importantly, MVB072 labeling displays the same altered activity profile upon salt treatment as MV151 labeling (Figure 4A). Quantification of fluorescence intensities of the various signals demonstrate a highly reproducible increased intensity of the upper signal at $6 \mathrm{~h}$ upon $250 \mathrm{mM} \mathrm{NaCl}$ treatment over

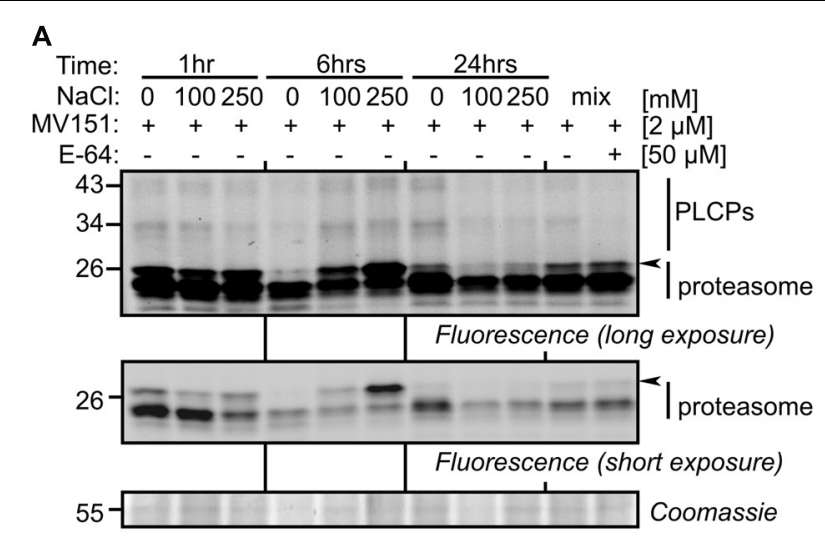

B

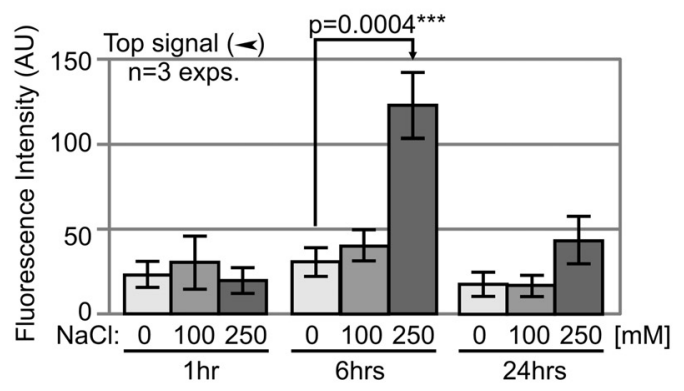

C

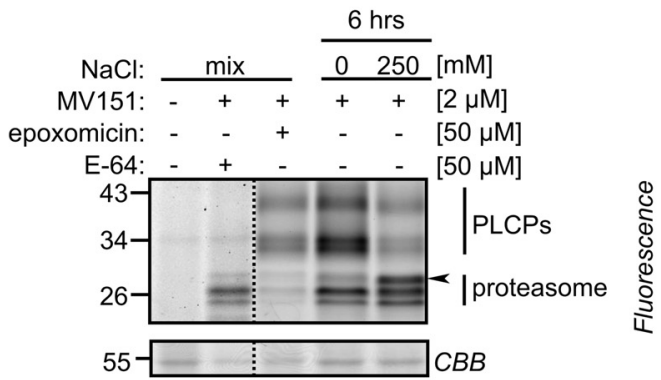

FIGURE 3 | MV151 activity profile changes upon salt stress in roots. (A) Differential activity profiles with MV151. Tomato roots were treated with 0-, 100-, $250 \mathrm{mM} \mathrm{NaCl}$. Root extracts were generated after 1-, 6- and $24 \mathrm{~h}$ and labeled with $2 \mu \mathrm{M}$ MV151 at $\mathrm{pH}$ 6.0. A mix of all nine samples was pre-incubated with or without $50 \mu \mathrm{M} \mathrm{E-64}$ and labeled with $2 \mu \mathrm{M} \mathrm{MV} 151$. Shown is a representative gel at long and short fluorescence exposure and upon coomassie staining. The other two experimental replicates are shown as Supplementary Figure S2. (B) Quantification of the upper differential MV151 signal (arrowhead) taken from three experimental replicates (A)

(Supplementary Figure S2). Error bars represent SEM of $n=3$ experimental replicates. (C) Differential signal is suppressed by proteasome inhibitor. The $6 \mathrm{~h} 0$ - and $250 \mathrm{mM} \mathrm{NaCl}$ treated samples were labeled with $2 \mu \mathrm{M} \mathrm{MV} 151$. A mix of the two samples was pre-incubated with or without $50 \mu \mathrm{M}$ E-64 or epoxomicin and labeled with or without $2 \mu \mathrm{M}$ MV151.

multiple biological replicates, whilst other signals seem to reduce (Figure 4B).

\section{及2- and $\beta 5$ Catalytic Subunits Migrate at Different Molecular Weight (MW) upon Lethal Salt Stress}

To identify the differentially active catalytic subunits of the proteasome, we separated MVB072-labeled proteomes of roots 


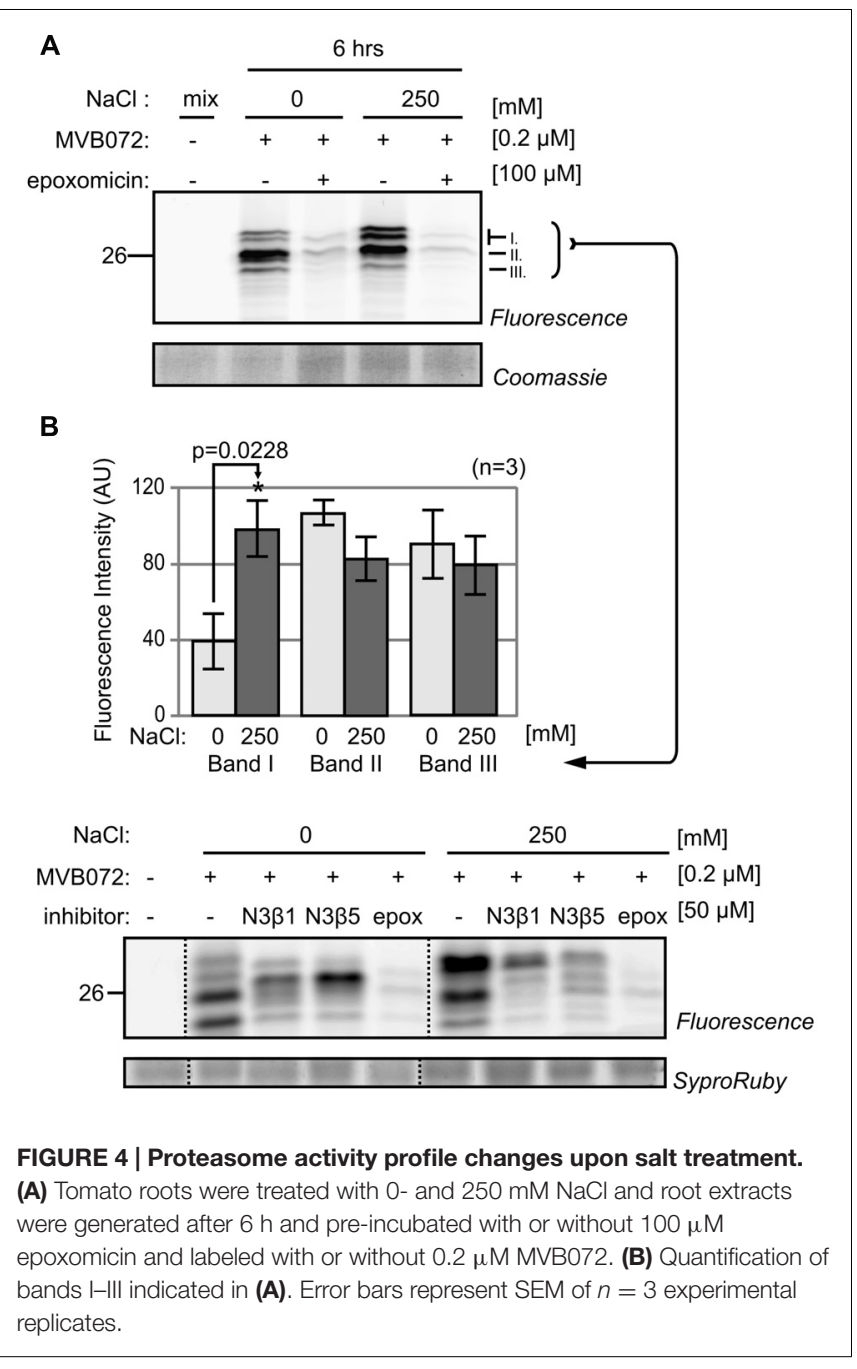

treated with and without $250 \mathrm{mM} \mathrm{NaCl}$ for $6 \mathrm{~h}$ by IEF and SDS gel electrophoresis. Over 14 fluorescent spots were robustly detected on 2D gels (Figure 5A). These fluorescent spots do not correlate with abundant proteins detected upon SYPRO Ruby staining of these gels (Supplementary Figure S3). The fluorescence intensity of each of these 14 spots was quantified using ImageJ and plotted in a histogram over three biological replicates (Figure 5B; Supplementary Figure S4). We detect significant increase of the fluorescence intensities of spots \#5 and $\# 13$ and a significant decrease of fluorescence intensities of spots \#8, \#10, \#11, \#13, and \#14, whilst fluorescence intensities of spots \#7 and \#9 were strongly increased upon salt treatment (Figure 5B). These changes in fluorescence intensities occurs in two regions in the $2 \mathrm{D}$ gel (boxed in Figure $\mathbf{5 A}$ ) and correlates with the shift in fluorescent intensity on $1 \mathrm{D}$ gels, as illustrated in Figure 5C. At the acidic pI range, five spots (\#711) showed reduced intensity upon salt stress, whilst one spot (\#5) has increased signal intensity (blue box in Figure 5C). At basic pI range, the bottom signal (\#14) decreases whilst the top signal (\#13) intensifies upon salt stress (red box in Figure 5C).
A total of 28 fluorescent spots were excised from both gels and analyzed by MS. Twenty-seven of these spots contain catalytic subunits of the proteasome (Supplementary Figures S4S6 and Table S1). In total, four different catalytic subunits were detected: Solyc07g016200.2.1 ( $\beta 1)$, Solyc04g024420.2.1 ( $\beta 2 \mathrm{a})$,

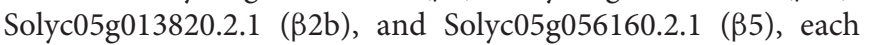
with multiple unique peptides and significant Mascot protein scores (Supplemental Figures S5-S6 and Table S2).

$\beta 2$ a was identified in spots $\# 5, \# 7$, and $\# 10$ in the control treatment and in spots \#4, \#5, and \#10 in the salt-treated sample (Figure 5D; Supplementary Figure S6). However, the majority of the MS signal in these spots comes from $\beta 2 \mathrm{~b}$ (Supplementary Figure S6). This indicates that $\beta 2 \mathrm{a}$ is part of the proteasome, but contributes only a minor fraction, irrespective of the stress condition. These data do not support the hypothesis that the stress proteasome has a different $\beta 2 \mathrm{a} / \beta 2 \mathrm{~b}$ ratio.

To assign the fluorescence signal to a particular catalytic subunit, we ranked the protein scores in Mascot for each spot and highlighted the four detected catalytic subunits. This analysis shows that we often identified more than one catalytic subunit from several spots (Figure 5D). The identification of multiple subunits per spot might be caused by incomplete separation during IEF or by contamination during gel excision. We assigned the signal to a single catalytic subunit in case a single subunit ranks consistently high in a spot. This way we assigned $\beta 1$ to spots $\# 1, \# 2$, \#3, and \#6; $\beta 2$ to \#4 and \#5; $\beta 5$ to \#13 and $\# 14$, and we found stronger signals for multiple subunits in the remaining spots (\#8-12; Figure 5E; Supplementary Figure S6). Taken together, these data indicate that salt stress induces a shift to a higher apparent MW for both labeled $\beta 2$ and $\beta 5$, and a shift to lower pI for labeled $\beta 5$.

\section{Subunit-Selective Probes Confirm Differential $\beta 5$ Activity Profile}

To confirm the identity of the shifting of the labeled catalytic subunits, the root extract was labeled with subunit-specific activity-based probes LW124 and MVB127 (Li et al., 2013; MisasVillamil et al., 2017). LW124 is specific for $\beta 1$ and has an epoxyketone reactive group and a fluorophore with excitation and emission wavelength at 470 and $530 \mathrm{~nm}$, respectively. By contrast, MVB127 is selective for $\beta 5$, carries a vinyl-sulfone reactive group and a fluorophore with excitation and emission wavelength at 532 and $580 \mathrm{~nm}$, respectively. As they have different specifies and their excitation and emission wavelength are different, LW124 and MVB127 can be used by co-labeling (MisasVillamil et al., 2017). Consistent with our earlier observations LW124 labeling does not display significant differences upon salt treatment, with the exception of on extra signal (arrowhead in Figure 6A). MVB127 labeling, however, shows a shift upward, confirming the MW shift of $\beta 5$ (Figure 6A).

To confirm the composition of the LW124- or MVB127labeled signals, we pre-incubated the samples with selective inhibitors, $N 3 \beta 1$ and $N 3 \beta 5$, which target $\beta 1$ and $\beta 5$, respectively (Misas-Villamil et al., 2017). N3 $\beta 1$ strongly suppressed labeling of LW124 ( $\beta 1)$, whilst N3 $\beta 5$ blocked labeling of MVB127 ( $\beta 5$ ), respectively, verifying that the top differential MV151- and 
A

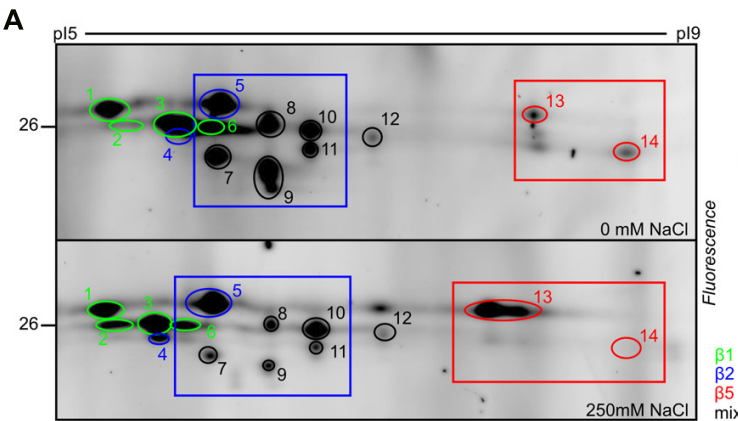

B

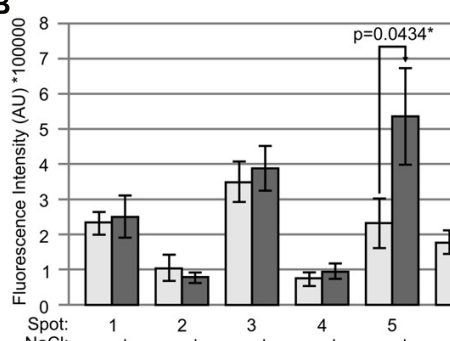

\section{C}
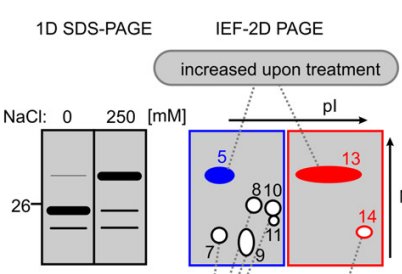

pl

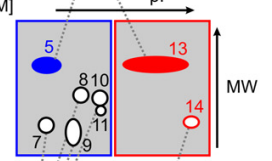

reduced upon treatment
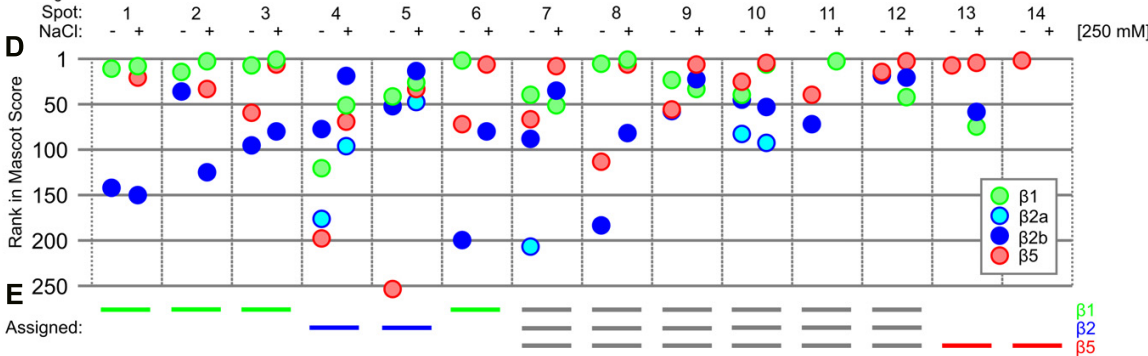

FIGURE 5 | Two-dimensional gels show molecular weight (MW) and pl shifts for labeled catalytic proteasome subunits. (A) Tomato roots were treated with 0 - and $250 \mathrm{mM} \mathrm{NaCl}$ and root extracts were generated after $6 \mathrm{~h}$ and labeled with $0.2 \mu \mathrm{M} \mathrm{MVB072.} \mathrm{Samples} \mathrm{were} \mathrm{separated} \mathrm{on} \mathrm{IEF} \mathrm{2D} \mathrm{gel.} \mathrm{Spots} \mathrm{are}$ highlighted with different colors: $\beta 1$ (green); $\beta 2$ (blue); and $\beta 5$ (red). Framed sections focus on $\beta 2$ (blue) and $\beta 5$ (red) catalytic subunits. (B) Quantification of the fluorescence signals of (A). Error bars represent SEM of $n=3$ experimental replicates. (C) Schematic figures of 1D and 2D gel illustrating the effect of high salinity on the intensity of signals of $\beta 2$ and $\beta 5$ catalytic subunits. Closed and open spots indicate up- and down-regulated signals, respectively. (D) Ranking of detected catalytic subunits based on Mascot protein scores. (E) Assignment of catalytic subunits to some of the fluorescent spots, based on the detected proteins and their scores and ranking.

MVB072 signals contains a $\beta 5$ subunit (Figure 6A). However, to a lesser extent, N3 $\beta 1$ also suppresses $\beta 5$ labeling and N3 $\beta 5$ suppresses $\beta 1$ labeling (Figure 6A), which can be explained by some cross reactivity of the inhibitors, but also by allosteric effects caused by subunit inhibition, including sterical hindrance in the proteolytic chamber.

To confirm the specific labeling and the $\mathrm{pI} / \mathrm{MW}$ shifts of the catalytic subunits, we analyzed LW124/MVB127 co-labeled samples on 2D IEF-PAGE gels. The labeling pattern confirms the MS data: spots in the acidic range are labeled with LW124, consistent with being $\beta 1$-derived signals, whereas the spots in the basic pI are labeled with MVB127, consistent with being $\beta 5$-derived (Figure 6B). We do not detect cross reactivity of LW124 on $\beta 5$, but there is some cross reactivity of MVB127 on $\beta 1$ (Figure 6B). Consistent with proceeding data, the MVB127labeled signals shift increase in MW and shift to more acidic pI upon salt treatment, even though in this case we detect some of this 'stress $\beta 5$ isoform' also in plants treated without salt (Figure 6B). By contrast, LW124-labeled signals are constant in the samples treated with or without salt, with the exception of one additional signal that correlates to the signal detected on $1 \mathrm{D}$ gels (arrowhead in Figures 6A,B). This confirms that most of labeled $\beta 1$ remains unaltered upon salt stress. Taken together, these data confirm a $\mathrm{pI} / \mathrm{MW}$ shift for labeled $\beta 5$ upon salt treatment.

\section{Molecular Weight Shift of Labeled $\beta 2$ or $\beta 5$ Is Not Affected by Phosphatase or Glycosidase Treatments}

Because of the shifts of denatured labeled $\beta 2$ and $\beta 5$ subunits when separated on $1 \mathrm{D}$ and $2 \mathrm{D}$ gels, we hypothesize that the MW is caused by a PTM of the labeled $\beta 2$ and $\beta 5$ subunits. Phosphorylation and glycosylation are two PTMs described for the proteasome (Bose et al., 2004; Zong et al., 2008; Scruggs et al., 2012). To test if the MW shifts are caused by phosphorylation, we treated the labeled samples with alkaline phosphatase. However, treatment of MVB072-labeled sample with alkaline phosphatase did not affect the shifted signal (Figure 7A). Probing the same extract with an antibody against phosphorylated MAP 


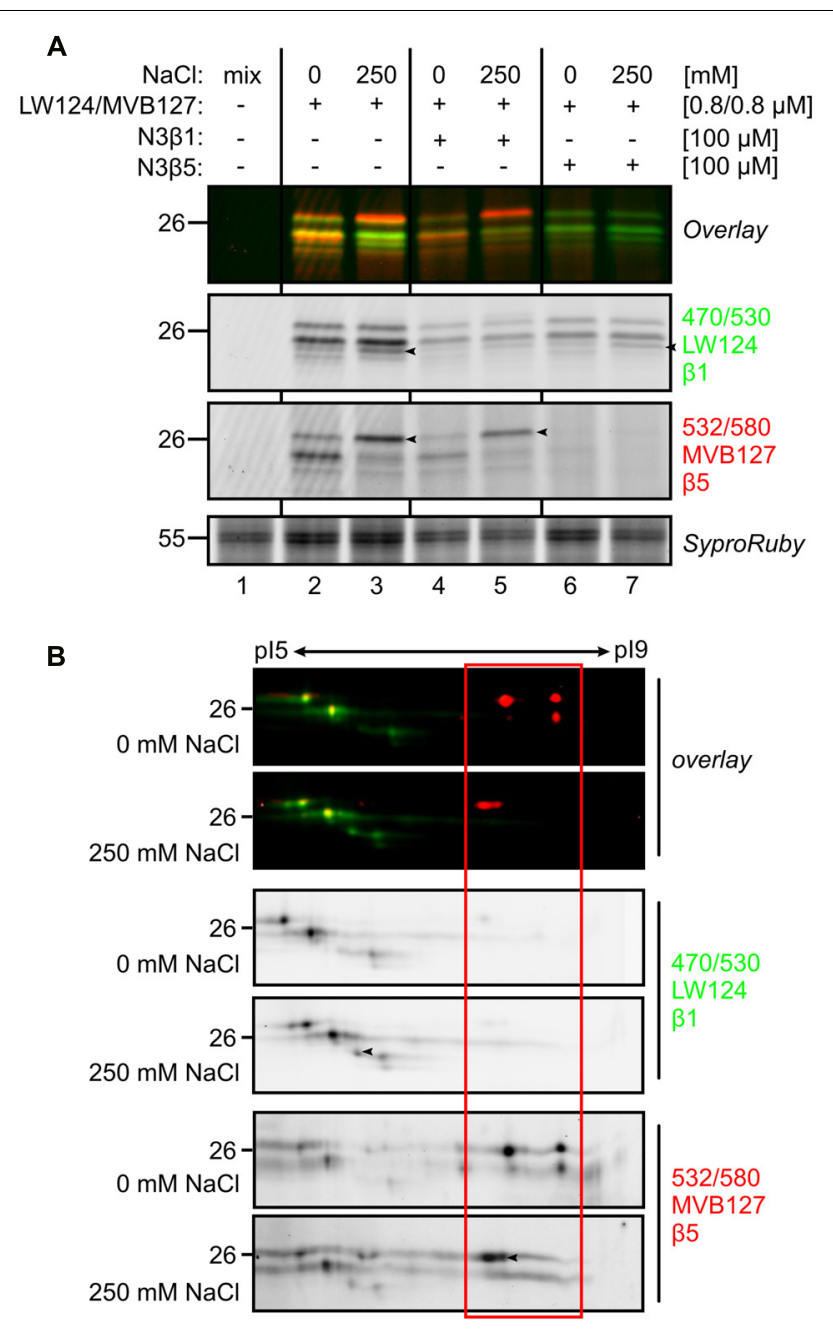

FIGURE 6 | Subunit-specific labeling confirms modification of $\beta 5$. (A) Tomato roots were treated with 0 - and $250 \mathrm{mM} \mathrm{NaCl}$ and root extracts were generated after $6 \mathrm{~h}$ and pre-incubated with or without subunit-specific inhibitors, N3 $\beta 1$ and N3 $\beta 5$ and co- labeled with or without subunit-selective probes, LW124 ( $\beta 1$ ) and MVB127 ( $\beta 5)$. Samples were separated on 1D gel. Differential signals are indicated by black arrowheads. (B) Tomato roots were treated with 0- and $250 \mathrm{mM} \mathrm{NaCl}$ and root extracts were generated after $6 \mathrm{~h}$ and co-labeled with LW124 ( $\beta 1)$ and MVB127 ( $\beta 5)$ and separated on IEF 2D gel. Differential signals are indicated by black arrowheads.

kinases showed a strong reduction, indicating that protein dephosphorylation worked in this assay (Figure 7B).

To test if the MW shifts are caused by differential glycosylation, we incubated the MVB072-labeled sample with PNGase $\mathrm{F}$ to remove $N$-glycans or with deglycosylation mix to remove both $\mathrm{N}$ - and $\mathrm{O}$-glycans using a mixture of PNGase F, O-Glycosidase, Neuraminidase, $\beta 1-4$ Galactosidase, en $\beta-N$ Acetylglucosaminidase. Neither of these treatments affected the labeling profile, suggesting that the MW shift is not caused by $\mathrm{N}$ - or O-glycosylation (Figure 7C). By contrast, Bovine Fetuin, a glycoprotein standard used as a positive control, did shift upon both treatments, indicating that deglycosylation worked in this assay (Figure 7D).

\section{DISCUSSION}

We discovered robust alteration in the activity profile of proteasome catalytic subunits during salt stress. Both labeled catalytic $\beta 2$ and $\beta 5$ subunits shifted to a higher MW and $\beta 5$ also has a negative $\mathrm{pI}$ shift upon salt stress. The recurrence of a normal proteasome profile at $24 \mathrm{~h}$ upon treatment with $250 \mathrm{mM} \mathrm{NaCl}$ indicates that this change is reversible and occurs concomitantly with PCD. The reason for proteasome modification could be an altered preference for substrates. Salt stress induces protein oxidation (Mano et al., 2014) and an altered proteasome would be required to degrade these oxidized proteins. The three catalytic subunits have different peptidase activity and their modification may cause changes in their activity and specificity.

There are several molecular mechanisms that might underpin $\mathrm{MW} / \mathrm{pI}$ shifts of catalytic subunits. In animals, standard proteasome subunits are replaced in nascent proteasome complexes by highly homologous $\beta 1 \mathrm{i}, \beta 2 \mathrm{i}$, and $\beta 5 \mathrm{i}$ subunits, which more efficiently produce antigenic peptides in response to infection (Tanaka and Kasahara, 1998) and more efficiently degrade oxidized proteins (Seifert et al., 2010). Replacements by the $\mathrm{i}-20 \mathrm{~S}$ proteasome subunits open the central chamber to allow access of more proteins to the catalytic core (Groettrup et al., 2010). Also, the immunoproteasome has reduced caspase-like activity (Ferrington and Gregerson, 2012). The existence of an immunoproteasome in tobacco was strongly suggested by the stress-induced accumulation of transcripts encoding $\beta 1, \alpha 3$, and $\alpha 6$ subunits (Suty et al., 2003). We can, however, exclude the mechanism of subunit replacement in tomato because tomato has single genes encoding six of the seven $\beta$ subunits. Tomato carries two genes encoding substantially different $\beta 2$ subunits, but our MS analysis did not suggest a changed subunit assembly upon salt stress. However, although different genes encoding the different $\beta 5$ isoforms can be excluded, alternative splicing could still result in different $\beta 5$ isoforms from the same gene. In animals, for instance, alternative splicing of transcripts encoding proteasome subunits can alter the activity and substrate specificity of $20 \mathrm{~S}$ proteasome (Kawahara et al., 2000).

\section{Post-translational Regulation of the Proteasome}

Post-translational modification is a likely molecular mechanism underpinning the shift in MW and pI of catalytic subunits. In animals, multiple PTMs have been described for proteasome subunits such as phosphorylation, glycosylation, ubiquitination, oxidation, glutathionylation, and nitrosylation (Bose et al., 2004; Ventadour et al., 2007; Zong et al., 2008; Scruggs et al., 2012; Cui et al., 2014). PTMs can regulate the stability of the proteasome, alter the assembly of different subunits and change the degradation pattern of proteasome or activity profile of catalytic subunits (Bose et al., 2004).

First, protein phosphorylation can cause both MW and pI changes (Zong et al., 2008). Phosphorylation of a serine residue in the $\alpha 6$ subunit has been studied in root tips of rice (Umeda et al., 1997). Phosphorylation also likely causes a mass increment of $\beta 1$ din during the induction of defense in tobacco 
A

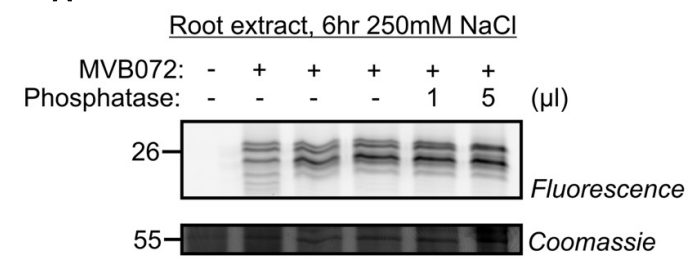

B

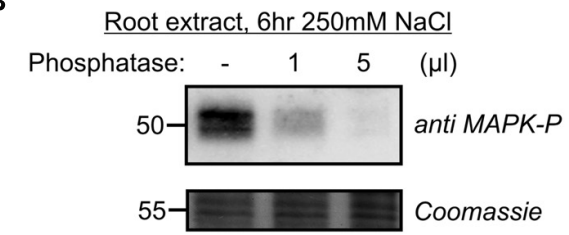

C

$\underline{\text { Root extract, } 6 \mathrm{hr} 250 \mathrm{mM} \mathrm{NaCl}}$

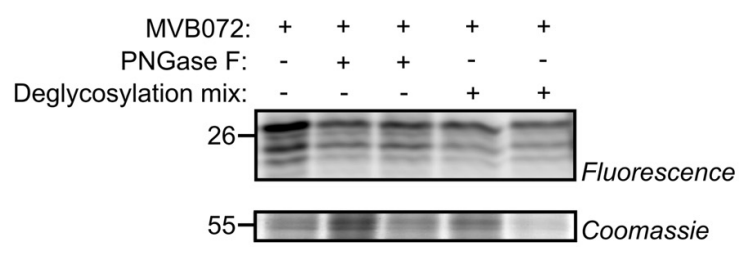

D

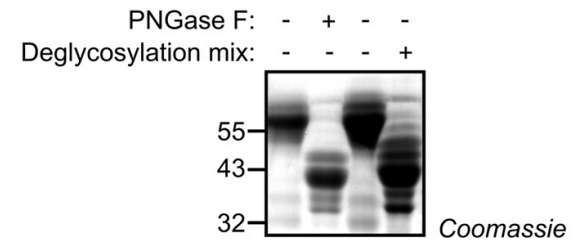

FIGURE 7 | Phosphatase and glycosidase treatments do not affect altered proteasome activity profile. (A) Root extracts of $250 \mathrm{mM}$ treated samples, labeled by MVB072 were treated with alkaline phosphatase at different conditions. (B) Dephosphorylation of MAP kinase, used as a positive control, detected by an anti-phosphoMAPK antibody. (C) Root extracts of $250 \mathrm{mM}$ treated-samples, labeled by MVB072 were treated with and without PNGase F or deglycosylation mix. (D) Enzymatic deglycosylation of Bovine Fetuin was used as a positive control.

(Suty et al., 2003). There are several predicted phosphorylation sites in catalytic subunits. The $\beta 2$ subunit contains eight Ser, five Thr, four Tyr residues, whereas the $\beta 5$ subunit contains 10 Ser, one Thr, and three Tyr residues (Supplementary Figure S3). However, searches or our MS data allowing phosphate modifications, did not reveal any phosphorylated peptides from the $\beta 2$ or $\beta 5$ subunits. In addition, phosphatase treatment did not affect the MVB072 activity profile in tomato roots upon $250 \mathrm{mM}$ $\mathrm{NaCl}$ treatment (Figure 7A) suggesting that phosphorylation is not the underlying mechanism of the altered proteasome upon salt stress. However, phosphorylation cannot be ruled out because some phosphorylations can endure alkaline phosphatase treatment.

Second, proteasome subunits can be regulated by glycosylation. For instance $O$-Glycosylation reversibly inhibits proteasome function via modification of Rpt2 ATPase in the $19 S$ regulatory particle of the proteasome in animals (Zhang et al., 2003). Likewise, $N$-Glycosylation is a key PTM of specific proteins during osmotic stress adaptation in plants (Koiwa et al., 2003). However, deglycosylation by PNGase or deglycosidase mix had no effect on the MW shift of $\beta 5$ (Figure 7C) indicating that also glycosylation is not the underlying mechanism.

Third, ubiquitination is common on proteasome subunits. Both $\beta 2$ and $\beta 5$ catalytic subunits are ubiquitinated at Lys residues (Ventadour et al., 2007; Kim et al., 2013). However, the predicted MW shift of mono- or polyubiquitinated $\beta 2$ and $\beta 5$ is too large (>8.5 kDa) to explain the observed $\sim 2 \mathrm{kDa}$ MW shift in the altered proteasome. The same argument excludes sumoylation as a PTM underlying the observed shifts in MW.

In addition, ROS production leads to accumulation of oxidatively modified proteins (e.g., carbonyl compounds) that alter the function of enzymes (Basset et al., 2002). There is evidence of carbonylation of the $20 \mathrm{~S}$ proteasome in response to carbon starvation in maize root tips (Basset et al., 2002). Furthermore, glutathionylation has been detected on each of the $\beta 5$ subunits of the plant proteasome (Dixon et al., 2005). $\beta 2$ has four and $\beta 5$ has two $C y s$ residues which may explain a $2 \mathrm{kDa}$ upon $S$-glutathionylation. Finally, $C y s$ residues can also be modified by reactive nitrogen species, which are released during stress (Hess et al., 2005). However, the use of reducing agents during our sample preparation would probably remove oxidation, glutathionylation, and nitrosylation from $C y s$ residues, so these PTMs are not likely to explain the MW/pI shifts that we detected. However, many additional PTMs are known and they can also be combined in several ways. Also a combination of PTMs might result in the observed MW/pI shifts in the activity profile of $\beta 2$ and $\beta 5$ catalytic subunits.

\section{CONCLUSION}

We discovered an altered proteasome activity profile at the early stage of salt stress-induced PCD in tomato roots. Modification of proteasome profile is probably caused by yet unidentified covalent modification of $\beta 2$ and $\beta 5$ proteasome catalytic subunits, which is not caused by differential subunit assembly, and may not be caused by phosphorylation, glycosylation or ubiquitination of catalytic subunits. This modification of the proteasome catalytic subunits is reversible and correlates with the need to degrade oxidized proteins during biotic and abiotic stress. Further work can now focus at the structural and functional elucidation of the stress-induced proteasome to determine its role in stress responses in plants.

\section{DATA AVAILABILITY}

The mass spectrometry proteomics data have been deposited to the ProteomeXchange Consortium via the PRIDE (Vizcaíno et al., 2016) partner repository (https://www.ebi.ac.uk/pride/archive/) 
with the dataset identifier PXD005266. The samples have been renamed as summarized in Supplementary Table S3.

\section{AUTHOR CONTRIBUTIONS}

JK, BC, TH, and RvdH designed experiments. JK performed most experiments. PP performed microscopy. FK performed mass spectrometry. JK, FK, JM-V, and RvdH analyzed the data. BX, $\mathrm{MK}$, and HO contributed materials. JK and RvdH wrote the manuscript with suggestions from all coauthors. IT and RvdH supervised the project.

\section{FUNDING}

This work was financially supported by grants from the Hungarian National Scientific Research Foundation (OTKA K101243), the European Union and the State of Hungary, co-financed by the European Social Fund in the framework of TÁMOP 4.2.4. A/2-11-1-2012-0001 'National Excellence

\section{REFERENCES}

Aki, M., Shimbara, N., Takashina, M., Akiyama, K., Kagawa, S., Tamura, T., et al. (1994). Interferon-gamma induces different subunit organizations and functional diversity of proteasomes. J. Biochem. 115, 257-269.

Andronis, E. A., and Roubelakis-Angelakis, K. A. (2010). Short-term salinity stress in tobacco plants leads to the onset of animal-like PCD hallmarks in planta in contrast to long-term stress. Planta 231, 437-448. doi: 10.1007/s00425-0091060-x

Bagniewska-Zadworna, A., and Arasimowicz-Jelonek, M. (2016). The mystery of underground death: cell death in roots during ontogeny and in response to environmental factors. Plant Biol. 18, 171-184. doi: 10.1111/plb.12391

Basset, G., Raymond, P., Malek, L., and Brouquisse, R. (2002). Changes in the expression and the enzymatic properties of the $20 \mathrm{~S}$ proteasome in sugar-starved maize roots. Evidence for an in vivo oxidation of the proteasome. Plant Physiol. 128, 1149-1162. doi: 10.1104/pp.010612

Biasini, M., Bienert, S., Waterhouse, A., Arnold, K., Studer, G., Schmidt, T., et al. (2014). SWISS-MODEL: modelling protein tertiary and quaternary structure using evolutionary information. Nucleic Acids Res. 42, W252-W258. doi: 10. 1093/nar/gku340

Bose, S., Stratford, F. L. L., Broadfoot, K. I., Mason, G. G. F., and Rivett, A. J. (2004). Phosphorylation of $20 S$ proteasome alpha subunit C8 $(\alpha 7)$ stabilizes the $26 \mathrm{~S}$ proteasome and plays a role in the regulation of proteasome complexes by $\gamma$-interferon. Biochem. J. 378, 177-184. doi: 10.1042/bj20031122

Cho, S. K., Ryu, M. Y., Song, C., Kwak, J. M., and Kim, W. T. (2008). Arabidopsis PUB22 and PUB23 are homologous U-Box E3 ubiquitin ligases that play combinatory roles in response to drought stress. Plant Cell 20, 1899-1914. doi: 10.1105/tpc.108.060699

Coux, O. (1996). Structure and functions of the $20 \mathrm{~S}$ and $26 \mathrm{~S}$ proteasomes. Annu. Rev. Biochem. 65, 801-847. doi: 10.1146/annurev.biochem.65.1.801

Cravatt, B. F., Wright, A. T., and Kozarich, J. W. (2008). Activity-based protein profiling: from enzyme chemistry to proteomic chemistry. Annu. Rev. Biochem. 77, 383-414. doi: 10.1146/annurev.biochem.75.101304.124125

Cui, Z., Scruggs, S. B., Gilda, J. E., Ping, P., and Gomes, A. V. (2014). Regulation of cardiac proteasomes by ubiquitination, SUMOylation, and beyond. J. Mol. Cell. Cardiol. 71, 32-42. doi: 10.1016/j.yjmcc.2013.10.008

Dixon, D. P., Skipsey, M., Grundy, N. M., and Edwards, R. (2005). Stress-induced proteins S-glutathionylation in Arabidopsis. Plant Physiol. 138, 2233-2244. doi: 10.1104/pp.104.058917

Ferrington, D. A., and Gregerson, D. S. (2012). Immunoproteasomes: structure, function, and antigen presentation. Prog. Mol. Biol. Transl. Sci. 109, 75-112. doi: 10.1016/B978-0-12-397863-9.00003-1
Program.' ERC Consolidator Grant 616449 'GreenProteases,' Max Planck Society for Plant Breeding Research in Cologne and the University of Oxford.

\section{ACKNOWLEDGMENTS}

We would like to thank Hölger Kramer for his help with 2D protein gel electrophoresis, and Jiorgos Kourelis for help with bioinformatic analysis. We would like to thank Zsuzsa Koncz for critically reading the manuscript.

\section{SUPPLEMENTARY MATERIAL}

The Supplementary Material for this article can be found online at: http://journal.frontiersin.org/article/10.3389/fpls.2017.00107/ full\#supplementary-material

TABLE S1 | Peptides and proteins of tomato detected by MS in 2D gels.

Gémes, K., Poór, P., Horváth, E., Kolbert, Z., Szopkó, D., Szepesi, A., et al. (2011) Cross-talk between salicylic acid and $\mathrm{NaCl}$-generated reactive oxygen species and nitric oxide in tomato during acclimation to high salinity. Physiol. Plant. 142, 179-192. doi: 10.1111/j.1399-3054.2011.01461.x

Giannattasio, S., Atlante, A., Antonacci, L., Guaragnella, N., Lattanzio, P., Passarella, S., et al. (2008). Cytochrome c is released from coupled mitochondria of yeast en route to acetic acid-induced programmed cell death and can work as an electron donor and a ROS scavenger. FEBS Lett. 582, 1519-1525. doi: 10.1016/j.febslet.2008.03.048

Grigoreva, T. A., Tribulovich, V. G., Garabadzhiu, A. V., Melino, G., and Barlev, N. A. (2015). The $26 \mathrm{~S}$ proteasome is a multifaceted target for anti-cancer therapies. Oncotarget 6, 24733-24749. doi: 10.18632/oncotarget.4619

Groettrup, M., Kirk, C. J., and Basler, M. (2010). Proteasomes in immune cells: more than peptide producers? Nat. Rev. Immunol. 10, 73-78. doi: 10.1038/ nri2687

Groll, M., Schellenberg, B., Bachmann, A. S., Archer, C. R., Huber, R., Powell, T. K., et al. (2008). A plant pathogen virulence factor inhibits the eukaryotic proteasome by a novel mechanism. Nature 452, 755-758. doi: 10.1038/ nature 06782

Gu, C., Kolodziejek, I., Misas-Villamil, J., Shindo, T., Colby, T., Verdoes, M., et al. (2010). Proteasome activity profiling: a simple, robust and versatile method revealing subunit-selective inhibitors and cytoplasmic, defense induced proteasome activities. Plant J. 62, 160-170. doi: 10.1111/j.1365-313X.2009. 04122.x

Gu, C., Shabab, M., Strasser, R., Wolters, P. J., Shindo, T., Niemer, M., et al. (2012). Post-translational regulation and trafficking of the granulin-containing protease RD21 of Arabidopsis thaliana. PLoS ONE 7:e32422. doi: 10.1371/ journal.pone.0032422

Hasegawa, P. M., Bressan, R. A., Zhu, J. K., and Bohnert, H. J. (2000). Plant cellular and molecular responses to high salinity. Annu. Rev. Plant Phys. 51, 463-499. doi: 10.1146/annurev.arplant.51.1.463

Hess, D. T., Matsumoto, A., Kim, S. O., Marshall, H. E., and Stamler, J. S. (2005). Protein S-nitrosylation: purview and parameters. Nat. Rev. Mol. Cell Biol. 6, 150-166. doi: 10.1038/nrm1569

Huh, G. H., Damsz, B., Matsumoto, T. K., Reddy, M. P., Rus, A. M., Ibeas, J. I., et al. (2002). Salt causes ion disequilibrium-induced programmed cell death in yeast and plants. Plant J. 29, 649-659. doi: 10.1046/j.0960-7412.2001. 01247.x

Kaschani, F., Gu, C., Niessen, S., Hoover, H., Cravatt, B. F., and Van der Hoorn, R. A. L. (2009). Diversity of serine hydrolase activities of unchallenged and botrytis-infected Arabidopsis thaliana. Mol. Cell. Proteom. 8, 1082-1093. doi: 10.1074/mcp.M800494-MCP200 
Kawahara, H., Kasahara, M., Nishiyama, A., Ohsumi, K., Goto, T., Kishimoto, T., et al. (2000). Developmentally regulated, alternative splicing of the Rpn 10 gene generates multiple forms of $26 \mathrm{~S}$ proteasomes. EMBO J. 19, 4144-4153. doi: 10.1093/emboj/19.15.4144

Kim, D. Y., Scalf, M., Smith, L. M., and Vierstra, R. D. (2013). Advanced proteomic analyses yield a deep catalog of ubiquitylation targets in Arabidopsis. Plant Cell 25, 1523-1540. doi: 10.1105/tpc.112.108613

Klare, N., Seeger, M., Janek, K., Jungblut, P. R., and Dahlmann, B. (2007). Intermediate-type $20 \mathrm{~S}$ proteasomes in HeLa Cells: "Asymmetric" subunit composition, diversity and adaptation. J. Mol. Biol. 373, 1-10. doi: 10.1016/j. jmb.2007.07.038

Koiwa, H., Li, F., McCully, M. G., Mendoza, I., Koizumi, N., Manabe, Y., et al. (2003). The STT3a subunit isoform of the Arabidopsis oligosaccharyltransferase controls adaptive responses to salt/osmotic stress. Plant Cell 15, 2273-2284. doi: $10.1105 /$ tpc. 013862

Kolodziejek, I., Misas-Villamil, J. C., Kaschani, F., Clerc, J., Gu, C., Krahn, D., et al. (2011). Proteasome activity imaging and profiling characterizes bacterial effector syringolin A. Plant Physiol. 155, 477-489. doi: 10.1104/pp.110. 163733

Kurepa, J., and Smalle, J. A. (2008). Structure, function and regulation of plant proteasomes. Biochemie 90, 324-335. doi: 10.1016/j.biochi.2007.07.019

Kurepa, J., Toh-E, A., and Smalle, J. A. (2008). 26S proteasome regulatory particle mutants have increased oxidative stress tolerance. Plant J. 53, 102-114. doi: 10.1111/j.1365-313X.2007.03322.x

Lequeu, J., Simon-Plas, F., Fromentin, J., Etienne, P., Petitot, A. S., Blein, J. P., et al. (2005). Proteasome comprising a $\beta 1$ inducible subunit acts as a negative regulator of NADPH oxidase during elicitation of plant defense reactions. FEBS Lett. 579, 4879-4886. doi: 10.1016/j.febslet.2005.07.073

Li, N., Kuo, C. L., Paniagua, G., Van den Elst, H., Verdoes, M., Willems, L. I., et al. (2013). Relative quantification of proteasome activity by activity-based protein profiling and LC-MS/MS. Nat. Protoc. 8, 1155-1168. doi: 10.1038/nprot. 2013.065

Löwe, J., Stock, D., Jap, B., Zwickl, P., Baumeister, W., and Hubert, R. (1995). Crystal structure of the $20 \mathrm{~S}$ proteasome from the archaeon T. acidophilum at 3.4 A resolution. Science 268, 533-539. doi: 10.1126/science.7725097

Maiolica, A., Borsotti, D., and Rappsilber, J. (2005). Self-made frits for nanoscale columns in proteomics. Proteomics 5, 3847-3850. doi: 10.1002/pmic.200402010

Mano, J., Nagata, M., Okamura, S., Shiraya, T., and Mitsui, T. (2014). Identification of oxidatively modified proteins in salt-stressed Arabidopsis: a carbonyltargeted proteomics approach. Plant Cell Physiol. 55, 1233-1244. doi: 10.1093/ pcp/pcu072

Michalski, A., Damoc, E., Lange, O., Denisov, E., Nolting, D., Müller, M., et al. (2012). Ultra high resolution linear ion trap orbitrap mass spectrometer (orbitrap elite) facilitates top down LC MS/MS and versatile peptide fragmentation modes. Mol. Cell. Proteomics 11, O111.013698. doi: 10.1074/ mcp.O111.013698

Misas-Villamil, J. C., Kolodziejek, I., Crabill, E., Kaschani, F., Niessen, S., Shindo, T., et al. (2013a). Pseudomonas syringae pv. syringae uses proteasome inhibitor syringolin A to colonize from wound infection sites. PLoS Pathog. 9:e1003281. doi: 10.1371/journal.ppat.1003281

Misas-Villamil, J. C., Toenges, G., Kolodziejek, I., Sadaghiani, A. M., Kaschani, F., Colby, T., et al. (2013b). Activity profiling of vacuolar processing enzymes reveals a role for VPE during oomycete infection. Plant J. 73, 689-700. doi: $10.1111 /$ tpj.12062

Misas-Villamil, J. C., van der Burgh, A. M., Grosse-Holz, F., Bach-Pages, M., Kovács, J., Kaschani, F., et al. (2017). Subunit-selective proteasome activity profiling uncovers uncoupled proteasome subunit activities during bacterial infections. Plant J. (in press).

Morimoto, K., and Van der Hoorn, R. A. L. (2016). The increasing impact of activity-based protein profiling in plant science. Plant Cell Physiol. 57, 446-461. doi: 10.1093/pcp/pcw003

Murata, S., Sasaki, K., Kishimoto, T., Niwa, S., Hayashi, H., Takahama, Y., et al. (2007). Regulation of CD8+ T cell development by thymus-specific proteasomes. Science 316, 1349-1353. doi: 10.1126/science.1141915

Murata, S., Yashiroda, H., and Tanaka, K. (2009). Molecular mechanisms of proteasome assembly. Mol. Cell. Biol. 10, 104-115.

Olsen, J. V., de Godoy, L. M., Li, G., Macek, B., Mortensen, P., Pesch, R., et al. (2005). Parts per million mass accuracy on an Orbitrap mass spectrometer via lock mass injection into a C-trap. Mol. Cell. Proteomics 4, 2010-2021. doi: 10.1074/mcp.T500030-MCP200

Perkins, D. N., Pappin, D. J., Creasy, D. M., and Cottrell, J. S. (1999). Probabilitybased protein identification by searching sequence databases using mass spectrometry data. Electrophoresis 20, 3551-3567. doi: 10.1002/(SICI)15222683(19991201)20:18<3551::AID-ELPS3551<3.0.CO;2-2

Poór, P., Borbély, P., Kovács, J., Papp, A., Szepesi, Á, Takács, Z., et al. (2014). Opposite extremes in ethylene/nitric oxide ratio induce cell death in suspension culture and root apices of tomato exposed to salt stress. Acta Biol. Hung. 65, 428-438. doi: 10.1556/ABiol.65.2014.4.7

Poór, P., Gémes, K., Horváth, F., Szepesi, Á., Simon, M. L., and Tari, I. (2011). Salicylic acid treatment via the rooting medium interferes with stomatal response, $\mathrm{CO}_{2}$ fixation rate and carbohydrate metabolism in tomato, and decreases harmful effects of subsequent salt stress. Plant Biol. 13, 105-114. doi: 10.1111/j.1438-8677.2010.00344.x

Rappsilber, J., Mann, M., and Ishihama, Y. (2007). Protocol for micropurification, enrichment, pre-fractionation and storage of peptides for proteomics using StageTips. Nat. Protoc. 2, 1896-1906. doi: 10.1038/nprot.2007. 261

Scruggs, S. B., Zong, N. C., Wang, D., Stefani, E., and Ping, P. (2012). Posttranslational modification of cardiac proteasomes: functional delineation enabled by proteomics. Am. J. Physiol. 303, H9-H18.

Seifert, U., Bialy, L. P., Ebstein, F., Bech-Otschir, D., Voigt, A., Schröter, F., et al. (2010). Immunoproteasomes preserve protein homeostasis upon interferon-induced oxidative stress. Cell 142, 613-624. doi: 10.1016/j.cell.2010. 07.036

Shabab, M., Shindo, T., Gu, C., Kaschani, F., Pansuriya, T., Chintha, R., et al. (2008). Fungal effector protein AVR2 targets diversifying defense-related Cys proteases of tomato. Plant Cell 20, 1169-1183. doi: 10.1105/tpc.107. 056325

Shabala, S. (2000). Ionic and osmotic components of salt stress specifically modulate net ion fluxes from bean leaf mesophyll. Plant Cell Environ. 23, 825-837. doi: 10.1046/j.1365-3040.2000.00606.x

Shabala, S. (2009). Salinity and programmed cell death: unravelling mechanisms for ion specific signaling. J. Exp. Bot. 60, 709-712. doi: 10.1093/jxb/erp013

Shevchenko, A., Tomas, H., Havlis, J., Olsen, J. V., and Mann, M. (2006). In-gel digestion for mass spectrometric characterization of proteins and proteomes. Nat. Protoc. 1, 2856-2860. doi: 10.1038/nprot.2006.468

Sueldo, D., Ahmed, A., Misas-Villamil, J. C., Colby, T., Tameling, W., Joosten, M. H. A. J., et al. (2014). Dynamic hydrolase activities precede hypersensitive tissue collapse in tomato seedlings. New Phytol. 203, 913-925. doi: 10.1111/nph. 12870

Suty, L., Lequeu, J., Lancon, A., Etienne, P., Petitot, A. S., and Blein, J. P. (2003). Preferential induction of $20 \mathrm{~S}$ proteasome subunits during elicitation of plant defense reactions: towards the characterization of "plant defense proteasomes." Int. J. Biochem. Cell Biol. 35, 637-650. doi: 10.1016/S1357-2725(02) 00386-2

Tanaka, K., and Kasahara, M. (1998). The MHC class I ligand-generating system: roles of immunoproteasomes and the interferon-Y-inducible proteasome activator PA28. Immunol. Rev. 163, 161-176. doi: 10.1111/j.1600-065X.1998. tb01195.x

The Tomato Genome Consortium (2012). The tomato genome sequence provides insights into fleshy fruit evolution. Nature 485, 635-641. doi: 10.1038/ nature11119

Umeda, M., Manabe, Y., and Uchimiya, H. (1997). Phosphorylation of the C2 subunit of the proteasome in rice (Oryza sativa L.). FEBS Lett. 403, 313-317. doi: 10.1016/S0014-5793(97)00073-2

van der Linde, K., Mueller, A. N., Hemetsberger, C., Kashani, F., Van der Hoorn, R. A. L., and Doehlemann, G. (2012). The maize cystatin CC9 interacts with apoplastic cysteine proteases. Plant Sign. Behav. 7, 1397-1401. doi: 10.4161/psb. 21902

Ventadour, S., Jarzaguet, M., Wing, S. S., Chambon, C., Combaret, L., Béchet, D., et al. (2007). A new method of purification of proteasome substrates reveals polyubiquitination of $20 \mathrm{~S}$ proteasome subunits. J. Biol. Chem. 282, 5302-5309. doi: 10.1074/jbc.M610005200

Vizcaíno, J. A., Csordas, A., del-Toro, N., Dianes, J. A., Griss, J., Lavidas, I., et al. (2016). 2016 update of the PRIDE database and related tools. Nucleic Acids Res. 44, 447-456. doi: 10.1093/nar/gkv1145 
Wang, S., Kurepa, J., and Smalle, J. A. (2009). The Arabidopsis $26 \mathrm{~S}$ proteasome subunit RPN1a is required for optimal plant growth and stress responses. Plant Cell Physiol. 50, 1721-1725. doi: 10.1093/pcp/ pcp105

Yee, D., and Goring, D. R. (2009). The diversity of plant U-box E3 ubiquitin ligases: from upstream activators to downstream target substrates. J. Exp. Bot. 60, 1109-1121. doi: 10.1093/jxb/ern369

Zhang, F., Su, K., Yang, X., Bowe, D. B., Paterson, A. J., and Kudlow, J. E. (2003). $\mathrm{O}-\mathrm{GlcNAc}$ modification is an endogenous inhibitor of the proteasome. Cell 115, 715-725. doi: 10.1016/S0092-8674(03)00974-7

Zheng, J., Dasgupta, A., and Bizzozero, O. A. (2012). Changes in 20S subunit composition are largely responsible for altered proteasomal activities in experimental autoimmune encephalomyelitis. J. Neurochem. 121, 486-494. doi: $10.1111 / j .1471-4159.2012 .07699 . x$

Zhu, J. K. (2001). Plant salt tolerance. Trends Plant Sci. 6, 66-71. doi: 10.1016/ S1360-1385(00)01838-0
Zong, C., Young, G. W., Wang, Y., Lu, H., Deng, N., Drews, O., et al. (2008). Two-dimensional electrophoresis-based characterization of post-translational modifications of mammalian $20 \mathrm{~S}$ proteasome complexes. Proteomics 8,5025 5037. doi: $10.1002 /$ pmic. 200800387

Conflict of Interest Statement: The authors declare that the research was conducted in the absence of any commercial or financial relationships that could be construed as a potential conflict of interest.

Copyright $\odot 2017$ Kovács, Poór, Kaschani, Chandrasekar, Hong, Misas-Villamil, Xin, Kaiser, Overkleeft, Tari and van der Hoorn. This is an open-access article distributed under the terms of the Creative Commons Attribution License (CC BY). The use, distribution or reproduction in other forums is permitted, provided the original author(s) or licensor are credited and that the original publication in this journal is cited, in accordance with accepted academic practice. No use, distribution or reproduction is permitted which does not comply with these terms. 